\title{
Vulnerability assessment in natural hazard and risk analysis: current approaches and future challenges
}

\author{
Sven Fuchs • Jörn Birkmann • Thomas Glade
}

Received: 7 August 2012/ Accepted: 9 August 2012/Published online: 19 August 2012

(C) Springer Science+Business Media B.V. 2012

\section{Introduction}

Negative consequences of natural hazards are the result of both the frequency and intensity of the hazard and the vulnerability of the society or element at risk exposed. Therefore, vulnerability assessment is an essential step to reduce these consequences and consequently natural hazard risk. The assessment of vulnerability requires an ability to both identify and understand the susceptibility of elements at risk and - in a broader sense-of the society to these hazards.

The concept of vulnerability is used today by various disciplines, and hence, it is embedded in multiple disciplinary theories underpinning either a technical or a social origin of the concept and resulting in a range of paradigms for either a qualitative or quantitative assessment of vulnerability. However, efforts to reduce the exposure to hazards and to create disaster-resilient communities require intersections among these theories (e.g. Hufschmidt and Glade 2010), since human activity cannot be seen independently from the environmental settings and vice versa. Acknowledging different roots of disciplinary paradigms, methods determining structural, economic, institutional or social vulnerability should be inter-woven in order to enhance our understanding of vulnerability and to adopt to ongoing global change processes.

Current approaches in vulnerability research are driven by a divide between social scientists and natural scientists, even if recently some attempts have been made within to

\author{
S. Fuchs $(\square)$ \\ Institute of Mountain Risk Engineering, University of Natural Resources and Life Sciences, Vienna, \\ Austria \\ e-mail: sven.fuchs@boku.ac.at \\ S. Fuchs \\ Faculty of Geography, Lomonosov Moscow State University, Moscow, Russian Federation \\ J. Birkmann \\ Institute for Environment and Human Security, United Nations University, Bonn, Germany \\ T. Glade \\ Institute of Geography and Regional Research, University of Vienna, Vienna, Austria
}


bridge this gap (e.g. Fuchs (2009) with respect to natural sciences and Renn (2008) focusing on social sciences). Whereas social scientists tend to view vulnerability as representing the set of socio-economic factors that determine people's ability to cope with stress or changes (cf. Wisner et al. 2004; Birkmann 2006; Field et al. 2012), natural scientists often view vulnerability in terms of the likelihood of occurrence of specific process scenarios and associated impacts on the built environment (e.g. Fell et al. 2008; Papathoma-Köhle et al. 2011). Representatives from each discipline define vulnerability in a way that fits to their individual disciplinary purposes.

This variety and diversity of definitions is also becoming apparent when reading through the individual chapters of this multidisciplinary special issue. This special issue on vulnerability is the result of a corresponding session entitled 'Vulnerability assessments in natural hazard and risk analysis', which was held at the General Assembly 2011 of the European Geosciences Union in Vienna, Austria. Out of this session, eight papers resulted, which are included in this issue.

The overarching thematic umbrella for the individual contributions of this special issue centres on the question of current approaches in vulnerability assessment, and future challenges that should be addressed in order to meet the requirements of sustainable development and adaptation to global change processes (Keiler et al. 2010). The issue contains different perspectives on vulnerability that are applicable on different scales and provides a forum for exchange-disciplinary foci are not necessarily poor if they are useful within specialised applications (Birkmann and Wisner 2006), as long as a mutual understanding for the approaches is acknowledged.

It has recently been stated that the challenge of vulnerability research is to integrate three different aspects (1) the components of vulnerability such as exposure, sensitivity or adaptive capacity, (2) the different methods used within different disciplines, and (3) the target dimension of vulnerability assessment (Fuchs et al. 2011). We therefore explicitly asked the authors (a) to discuss and outline their understanding of vulnerability in order to present a variety of current approaches in vulnerability assessment and (b) to formulate and deal with future challenges that may be addressed in order to get an in-depth knowledge on vulnerability taking a broader viewpoint and opening up perspectives beyond the ordinary.

\section{Overview about the individual contributions}

Anne Holsten and Jürgen Kropp address a climate change vulnerability assessment for the Federal State of North Rhine-Westphalia in Germany by means of tailor-made approaches for various sectors described by individual and collective physical, social, economic and environmental conditions. The total potential impact of climate change is expressed by the arithmetic mean of several sectoral impacts and is compared with an adaptive capacity to describe the vulnerability. Their spatial scale is the municipal level, and as such regions were identified, which will have to deal with a higher vulnerability to climate change and have therefore a higher need for adaptation than adjacent communities. The standardised approach developed allows for a comparative and integrated assessment of climate change impacts while sector-specific differences of impact-severity were shown. Their results give indications towards suitable intervention options in specific sectors and show prioritization regarding specific adaptation measures to reduce climate change vulnerability.

Taking a similar spatial approach, Stefan Kienberger is presenting a method to model economic and social vulnerability on the municipal level of Búzi, Mozambique. To address vulnerability, both information on the occurrence and distribution of hazards and data on 
the spatial distribution of elements at risk exposed were collected. The social and economic dimension of vulnerability was addressed in a spatial and integrative manner applying the geon approach. Homogenous vulnerability regions are identified through the application of integrated modelling approaches, which build on expert local knowledge and weightings. A set of indicators is proposed, which allow the modelling of vulnerability in an environment characterised by an overall lack in quantifying data. Different perceptions between national experts and local community members are visualised through maps, and opportunities of vulnerability reduction through adaptation are discussed. The results presented aim to facilitate the identification of locations with critical vulnerability, serving the needs for decision-makers and practitioners in disaster risk reduction.

Otar Varazanashvili, Nino Tsereteli, Avtandil Amiranashvili, Emil Tsereteli, Elizbar Elizbarashvili, Jemal Dolidze, Lado Qaldani, Manana Salukvadze, Shota Adamia, Nika Arevadze and Aleksandre Gvencadze report on the efforts recently undertaken to assess the vulnerability to multiple hazards on the national level of the Republic of Georgia. The method focused on a small-scale approach and was based on the development of a relational hazard database merging disaster frequencies and magnitudes with information on historically occurring economic losses for the country. The authors developed a framework for hazard and vulnerability assessment; based on individual hazard and vulnerability assessments, they showed how such information may be combined towards a multivulnerability and multirisk map for the entire country. Their contribution concludes with suggestions for future tasks to be undertaken to enhance the efforts of risk mitigation in the country.

Scira Menoni, Daniela Molinari, Dennis Parker, Francesco Ballio and Sue Tapsell assess vulnerability and resilience applying a method developed within the ENSURE project taking the city of Sondrio in the flash flood-prone catchment of Mallero, Italy, as an example. Based on a review of vulnerability indicators, the contribution claims a lack in comprehensively applicable indicators that may be used to assess weaknesses and resilience in coping with natural hazard risk. The vulnerability and resilience assessment framework tool presented adopts a systemic approach embedding and integrating as much as possible the multifaceted and articulated nature of concepts such as vulnerability and resilience. The tool guides evaluators towards a comprehensive and context-related understanding of strengths and fragilities of a given territory and community with respect to natural extremes. The results also suggest vulnerability reduction policies and actions and further ways of revising the existing framework tool in the future.

Focusing on a similar hazard type, Maria Papathoma-Köhle, Margreth Keiler, Reinhold Totschnig and Thomas Glade are taking another viewpoint with respect to scale and focus on the determination of constructive vulnerability of buildings exposed to torrent processes in Italy. A methodology for the development of a vulnerability curve as a function of the intensity of the process and the degree of loss-developed within the MOVE project-is presented. They argue that the curve can be a valuable tool in the hands of local authorities, emergency and disaster planners since it can assist decision-making and cost-benefit analysis of structural protection measures by assessing the potential cost of future events. Data documented during the 1987 debris flow event were used to create a vulnerability curve that shows the degree of loss corresponding to different process intensities. Although the validation process demonstrated the reliability of the results, improved damage assessment documentation is recommended and presented, which may advance the quality of the data and the reliability of the curve.

Wen-Chun Lo, Ting-Chi Tsao and Chih-Hao Hsu also focus on individual torrent events that occurred as a result of severe precipitation during the Typhoon season in Taiwan 
(ROC). Their study proposes a flowchart to establish vulnerability curves for buildings exposed through estimating the incurring damages after debris flow events. The losses of content and structure are firstly calculated separately to obtain the loss ratios with respect to original buildings. Secondly, by combining the content and structure loss ratio, the building vulnerability function is derived. The results show that due to a higher percentage of content value compared with the total building value, the loss ratio resulting from debris flows in Taiwan is higher compared with European studies, in particular with respect to high-frequency but low-magnitude events. The concept of obtaining building vulnerability is recommended for regions where well-documented loss data is unavailable.

Based on earlier studies (Fuchs et al. 2007; Totschnig et al. 2011) on the vulnerability of buildings exposed to torrent processes in the European Alps, Sven Fuchs, Christine Ornetsmuiller, and Reinhold Totschnig present an analysis of the spatial characteristics of vulnerability on a local scale since considerable ranges in the loss ratio for medium process intensities only provided a hint so far that there might be mutual reasons for lower or higher loss rates. In their paper, the focus is on the spatial dimension of vulnerability by searching for spatial clusters in the damage ratio of elements at risk exposed. Some significant clusters of high damage ratios and consequently high vulnerability were detected, and secondary clusters of high and low values were found in the test sites. Based on their results, the assumption that lower process intensities result in lower damage ratios, and therefore in lower vulnerability, and vice versa, has to be partly rejected. The spatial distribution of vulnerability is not only dependent on the process intensities but also on the overall land use pattern and the individual constructive characteristics of the buildings exposed.

Francesco Stecchi, Francesco Mancini, Claudia Ceppi and Giovanni Gabbianelli present a multicriteria approach to assess the vulnerability of buildings towards ground deformation phenomena resulting from salt deposits exploitation in the city of Tuzla, Bosnia and Herzegovina. The multicriteria approach is in particular suitable for regions with a poor damage record. Their approach to quantify vulnerability is able to define a discrete map with grid cells of $50 \times 50 \mathrm{~m}$ width report the most vulnerable parts of the town. The results offer to local decision-makers a starting point for an appropriate allocation of resources for a restoration of damages and towards a mitigation of risks to ground deformation affecting the residents.

\section{Current approaches}

By reviewing the contributions to this special issue, the first distinctive feature is related to the diversity of approaches to quantify vulnerability, which is (1) rooted in the different disciplinary conceptualisations of vulnerability but also (2) a result of the different spatial resolution of the studies carried out. The term vulnerability is closely related to natural hazards and is conceptualised in hazard and disaster management in various ways. As a consequence, the notion of vulnerability is as divergent as the methods and theories of disciplines involved in risk research. Nevertheless, the consequences of hazards were generally measured in terms of damage or losses, either on an ordinal scale based on social values or perceptions and evaluations, on matrices developed to include knowledge-based criteria or on a metric scale (e.g. in monetary units). For all studies, it can be argued that exposure as originator of vulnerability results in considerable economic vulnerability of structures, which is generated by the institutional settings of dealing with hazards and shaped by the overall societal framework (Fuchs 2009). Hence, if vulnerability and its 
counterpart, resilience, is analysed and evaluated by using a comprehensive approach, a better understanding of the vulnerability-influencing parameters will be achieved, taking into account the interdependencies and interactions between the disciplinary foci.

Within any domain of sciences, a distinct conceptual separation between vulnerability, hazard and risk can be observed (e.g. Hufschmidt and Glade 2010; Fuchs et al. 2011). From the perspective of social sciences, vulnerability is understood as a predisposition and potential of communities or individuals to be harmed; consequently, vulnerability does not change if the hazard is more intense or not-it is in contrast the exposure that might change and that influences the degree of being at risk. Initially, the focus in vulnerability research was on the internal side of vulnerability (exposure of communities or elements at risk exposed) and on the external side (coping capacity of people or systems) and to societal structures (Chambers 1989). Subsequently, it was increasingly regarded as more important to focus on the capacity of people to cope with and adapt to hazardous events and processes (Anderson 1995). Complimentary, natural scientists define vulnerability as the expected degree of loss resulting from the impact of a hazardous phenomenon of a given magnitude and frequency on elements at risk exposed. Natural science approaches therefore mostly focus on the susceptibility of physical elements at risk to natural processes (Varnes 1984; Papathoma-Köhle et al. 2011) in order to provide information necessary for operational risk analyses (Carter 1991) and mitigation (Holub and Fuchs 2009; Holub et al. 2012). Through the rise of research on the consequences of climate change, only recently an additional categorisation gained relevance that includes the components of exposure, sensitivity and adaptive capacity (Turner II et al. 2003).

Within this special issue, however, all contributions presented considerable advancements in their respective field of vulnerability research, spanning from developing vulnerability functions for a local scale (Lo et al., Papathoma-Köhle et al.) and a spatial statistics on vulnerability (Fuchs et al.) to local grid-based approaches resulting from multicriteria analyses (Stecchi et al.) and the spatial modelling of economic and social vulnerability (Kienberger), as well as regionally applicable approaches (Holsten and Kropp, Menoni et al.) and nation-wide applications (Varazanashvili et al.). A general difference can be made between rather deductive vulnerability assessments that aim at identifying, comparing and quantifying vulnerability of areas, groups or sectors by relying on different (empirically gained) indicators and indices and inductive vulnerability assessments aiming at a better understanding of the perceptions of vulnerabilities of actors and their capacities in order to develop locally embedded adaptation and coping strategies.

\section{Future challenges}

To manage natural hazard risk, a broader understanding of the concept of vulnerability is needed in order to reduce losses resulting from hazardous events. Multiple conceptualisations of vulnerability exist that show inherent differences in underlying theories due to sectoral disciplinary foci. A major challenge in vulnerability research is that "not only people are different, but they are changing continuously, both as individuals and as groups. This constant change within the human system (...) interacts with the physical system to make hazard, exposure, and vulnerability all quite dynamic" (Mileti 1999, p. 119). These changes lead to the postulate that the only consideration of either structural vulnerability, subject to the domain of natural scientists, or social vulnerability, subject to the domain of social scientists in a broader sense, is not sufficient to assess vulnerability comprehensively from an integrative point of view. In contrast, dimensions of susceptibility, presumably 
starting with the physical impact on elements at risk defined as structural vulnerability, further encompass institutional, economic and social aspects. Thereby, any damage occurring might be considered as prerequisite for structural and economic susceptibility, while institutional susceptibility and social aspects provide the framework for vulnerability in general. In this manner, multiple interactions between these conceptualisations of vulnerability exist. Acknowledging these different roots of the multiple concepts of vulnerability, it becomes apparent that only by a multidimensional approach, the overall aim of reducing natural hazards risk can be achieved. It is shown by the contributions to this special issue that disciplinary approaches in vulnerability assessment have intersections among each other, leading to the conclusion that structural, economic, institutional and social vulnerability are interdependent and interacting. A further improvement of the methods to assess vulnerability will help to meet the challenges for risk assessment arising from global change under the consideration of changing social systems and natural systems as well as complex interaction between both systems. Therefore, practical examples on how to assess dynamics and spatially specific features and configurations of vulnerability are needed. The special issue and the respective contributions might provide some first insights into these issues, and all readers are invited to further contribute to this scientific discussion.

Acknowledgments We would like to express our sincere thanks to the management and Editorial Board of Natural Hazards, above all Petra van Steenbergen, Senior Publishing Editor at Springer, Tad Murty as the Coordinating Editor, as well as Shabona Ramesh and her team from the Editorial Office of Springer. Moreover, we would like to acknowledge the sincere efforts of all the reviewers who supported this special issue with their knowledge on different aspects of vulnerability and their constructive criticism that helped us to further develop the individual argumentations in the papers. We would also like to thank all the colleagues who contributed to this special issue, above all for their patience during the process of manuscript production and revision.

\section{References}

Anderson M (1995) Vulnerability to disaster and sustainable development: a general framework for assessing vulnerability. In: Munasinghe M, Clarke C (eds) Disaster prevention for sustainable development: economic and policy issues. The International Bank for Reconstruction and Development, The World Bank, Washington, pp 41-59

Birkmann J (2006) Measuring vulnerability to natural hazards. UNU Press, Tokyo

Birkmann J, Wisner B (2006) Measuring the un-measurable. The challenge of vulnerability. Source 5/2006. United Nations University, Bonn

Carter W (1991) The disaster management cycle. In: Carter W (ed) Disaster management: a disaster manager's handbook. Asian Development Bank, Manila, pp 51-59

Chambers R (1989) Vulnerability, coping and policy. IDS Bull 20(2):1-7

Fell R, Corominas J, Bonnard C, Cascini L, Leroi E, Savage W (2008) Guidelines for landslide susceptibility, hazard and risk zoning for land-use planning. Eng Geol 102(3-4):85-98

Field CB, Barros V, Stocker TF, Dahe Q, Dokken DJ, Plattner G-K, Ebi KL, Allen SK, Mastrandrea MD, Tignor M, Mach KJ, Midgley PM (2012) Managing the risks of extreme events and disasters to advance climate change adaptation. Cambridge University Press, Cambridge

Fuchs S (2009) Susceptibility versus resilience to mountain hazards in Austria-paradigms of vulnerability revisited. Nat Hazards Earth Syst Sci 9(2):337-352

Fuchs S, Heiss K, Hübl J (2007) Towards an empirical vulnerability function for use in debris flow risk assessment. Nat Hazards Earth Syst Sci 7(5):495-506

Fuchs S, Kuhlicke C, Meyer V (2011) Editorial for the special issue: vulnerability to natural hazards-the challenge of integration. Nat Hazards 58(2):609-619

Holub M, Fuchs S (2009) Mitigating mountain hazards in Austria-legislation, risk transfer, and awareness building. Nat Hazards Earth Syst Sci 9(2):523-537 
Holub M, Suda J, Fuchs S (2012) Mountain hazards: reducing vulnerability by adapted building design. Environ Earth Sci 66(7):1853-1870

Hufschmidt G, Glade T (2010) Vulnerability analysis in geomorphic risk assessment. In: Alcántara-Ayala I, Goudie A (eds) Geomorphological hazards and disaster prevention. Cambridge University Press, Cambridge, pp 233-243

Keiler M, Knight J, Harrison S (2010) Climate change and geomorphological hazards in the eastern European Alps. Philos Trans R Soc Lond Ser A: Math Phys Eng Sci 368:2461-2479

Mileti D (1999) Disasters by design. Joseph Henry Press, Washington

Papathoma-Köhle M, Kappes M, Keiler M, Glade T (2011) Physical vulnerability assessment for alpine hazards: state of the art and future needs. Nat Hazards 58(2):645-680

Renn O (2008) Concepts of risk: an interdisciplinary review-part 2: integrative approaches. Gaia 17(2):196-204

Totschnig R, Sedlacek W, Fuchs S (2011) A quantitative vulnerability function for fluvial sediment transport. Nat Hazards 58(2):681-703

Turner B II, Kasperson R, Matson P, McCarthy J, Corell R, Christensen L, Eckley N, Kasperson J, Luers A, Martello M, Polsky C, Pulsipher A, Schiller A (2003) A framework for vulnerability analysis in sustainability science. Proc Natl Acad Sci USA 100(14):8074-8079

Varnes D (1984) Landslide hazard zonation: a review of principles and practice. UNESCO, Paris

Wisner B, Blaikie P, Cannon T, Davis I (2004) At risk. Natural hazards, people's vulnerability and disasters. Routledge, London 